\title{
Polymer Electrolytes for LIBs Based on Perfluorinated Sulfocationic Nepem-117 Membrane and Aprotic Solvents
}

Daria Voropaeva ${ }^{\mathrm{a}, \mathrm{b}}$, Svetlana Novikova ${ }^{* a}$, Tongwen $\mathrm{X} \mathrm{u}^{\mathrm{c}}$ and Andrey Yaroslavtsev ${ }^{\mathrm{a}, \mathrm{b}, \mathrm{d}}$

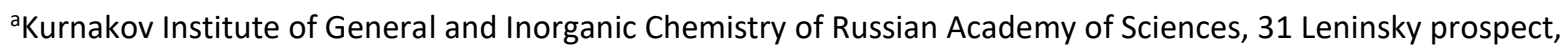
119991, Moscow, Russia

' Institute of Problems of Chemical Physics of Russian Academy of Sciences, Academician Semenov avenue 1, 142432, Chernogolovka, Russia

'School of Chemistry and Material Science, University of Science and Technology of China, Hefei, 230026 P. R. China

${ }^{\mathrm{d} N a t i o n a l ~ R e s e a r c h ~ U n i v e r s i t y ~ H i g h e r ~ S c h o o l ~ o f ~ E c o n o m i c s, ~ 101000, ~ M o s c o w, ~ R u s s i a ~}$

*Phone: +7(495)9522487; e-mail: novikova@igic.ras.ru

\section{Supported information}

Table S1. Permittivities $(\varepsilon)$, dynamic viscosities $(\eta)$, dipole moments $(\mu)$, melting and boiling points $\left(T_{m} / T_{b}\right)$ of the solvents utilized in LIBs and SIBs ${ }^{1-4}$

\begin{tabular}{|c|c|c|c|c|c|}
\hline solvent & $\begin{array}{l}\text { chemical } \\
\text { structure }\end{array}$ & $\varepsilon, 25^{\circ} \mathrm{C}$ & $\eta, 25^{\circ} \mathrm{C}, \mathrm{cP}$ & $\mu, D$ & $\mathrm{~T}_{\mathrm{m}} / \mathrm{T}_{\mathrm{b}},{ }^{\circ} \mathrm{C}$ \\
\hline EC & & 89.8 & $1.9\left(40^{\circ} \mathrm{C}\right)$ & 4.6 & $36 / 248$ \\
\hline PC & & 64.9 & 2.5 & 4.8 & $-50 / 242$ \\
\hline DMSO & & 45 & 1.9 & 4.0 & $18 / 189$ \\
\hline DMF & & 36.7 & 0.8 & 3.8 & $-61 / 153$ \\
\hline DMA & & 39 & 0.9 & 3.8 & $-20 / 165$ \\
\hline THF & & 7.5 & 0.5 & 1.6 & $-108 / 66$ \\
\hline
\end{tabular}


[1] Liu, Y.; Cai, Z. ; Tan, L. ; Li, L. Ion exchange membranes as electrolyte for high performance Li-ion batteries, Energy Environ. Sci. 2012, 5, 9007-9013.

[2] Yaws, Carl L. Thermophysical properties of chemicals and hydrocarbons. 2nd edit. Chapter 19, Elsevier, Amsterdam, 2014.

[3] Chernyak, Y. Dielectric constant, dipole moment, and solubility parameters of some cyclic acid esters, J. Chem. Eng. Data 2006, 51, 416-418.

[4] Aminabhavi, T.M. ; Gopalakrishna, B. Density, viscosity, refractive index, and speed of sound in aqueous mixtures of $\mathrm{N}, \mathrm{N}$-dimethylformamide, dimethyl Sulfoxide, N,N-dimethylacetamide, acetonitrile, ethylene glycol, diethylene glycol, 1,4-dioxane, tetrahydrofuran, 2-methoxyethanol, and 2-ethoxyethanol at 298.15 K, J. Chem. Eng. Data 1995, 40, 856-861.

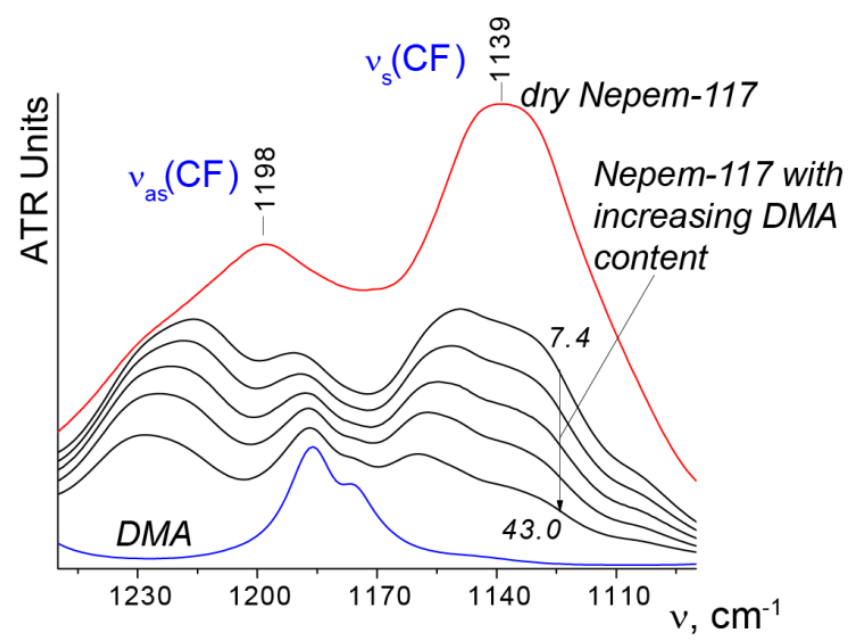

Figure S1. Fragments of IR spectra of DMA, a dry Nepem-117 membrane in the $\mathrm{Li}^{+}$form, and membranes with DMA uptake from 7.4 to 43.0 (indicated in the figure) showing the $v_{a s}(C F)$ and $v_{s}(C F)$ absorption bands.

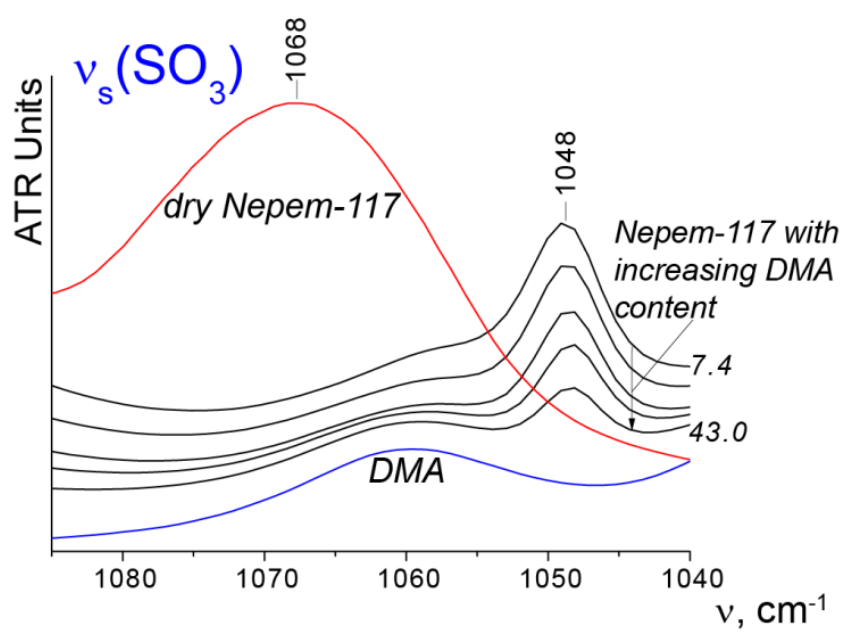

Figure S2. Fragments of IR spectra of DMA, a dry Nepem-117 membrane in the $\mathrm{Li}^{+}$form, and membranes with DMA uptake from 7.4 to 43.0 (indicated in the figure) showing the $\mathrm{v}_{s}\left(\mathrm{SO}_{3}\right)$ absorption band. 